the brain were deeply congested; on section a few minute red points were observed. The heart, the right side, was found dilated and contained dark-blue clotted blood; the left side was contracted and practically empty. There was a large deposit of fat, otherwise the heart was nor mal. The lungs on removal presented a dark congested and mottled appearance. On section, frothy exudation followed, the lung tissue was crepitant throughout. 'There was no disease of the lungs. The peritoneal surface of the stomach was of claret colour. On cutting the organ open it was found empty; the mucous membrane was thickened and congested in patches, especially towards the pyloric end-these patches were observed at intervals almost throughout the small intestine. The liver weighed seven pounds and a half. The kidneys were enlarged. The remaining organs were normal. The washings of the stomach presented the usual tests for cyanides. A few comments on the case may be made. Cases of poisoning by cyanide of potassium are of rare occurrence, though the salt is largely used by photographers. The few cases of poisoning which have occurred have been in connexion with this trade, as in this case. The salt is usually adulterated with carbonate of potash; probably this caused the signs of corrosive poisoning, whilst the cyanide of potassium itself was the immediate cause of death by paralysing the respiratory centre. There was a history of alcoholism of two years' duration; this intensified the congestion of the membranes of the brain, and would also account for the enlarged liver and disease of the kidneys. Blackpool.

\section{GANGRENE AFTER TYPHOID FEVER.}

\section{By William Gosse, L.R.C.P., D.P.H. Camb.}

Noticing Dr. Dawtry Drewitt's communication on the Rarity of Gangrene after Typhoid Fever, the following case occurring in the Murston epidemic may be of interest.

Fred. P-, aged eighteen years, a brickmaker, fair and spare, with family history of phthisis ; heart normal. The onset was sudden and influenza-like, with temperature occasionally reaching $105^{\circ} \mathrm{F}$.; but after the third week, when he was removed to the Infectious Hospital, it never exceeded $102^{\circ}$, and at the end of the fifth week of the fever it became normal. There was no excessive diarrhoea or hæmorrhage, but the patient was very asthenic and torpid. The convalescence was slow, with disinclination for exer tion, the feet and legs being odematous. At the third week of convalescence the dorsum of the left foot became first purple, then mottled and gangrenous, and extremely sensitive. Perchloride of iron and quinine were given, and boric fomentations applied to the foot and leg. In a few days a line of demarcation formed, enclosing an area of about twelve square inches. It was then poulticed with linseed-meal and carbolic oil. The slough came away in a week, exposing the tendons and muscles; this had nearly granulated up when the patient was discharged in the ninth week of convalescence. In considering the pathology of the case, the cedema appears due to cardiac weakness, as there were no varicose veins. The gradual onset points rather to thrombosis than to embolism of the anterior tibial artery, which is also rendered more probable by the fact of the patient being an amateur sprinter, the artery being supported by muscles until it reaches the ankle-joint, where it would be exposed to injury and strain, and where the occlusion most likely occurred. There was no sudden pain in the limb, such as would be caused by the impaction of an embolus.

Sittingbourne.

\section{TWO CASES OF CHLOROFORM NARCOSIS, WITH NECROPSIES.}

By F. KNowLES, L.R.C.P., M.R.C.S.

HAVING recently been called in by our coroner to examine two cases of death from chloroform, the following brief notes may be of interest.

The first case was that of a well-nourished woman, aged thirty-four, an idiot, who died after inhaling less than three drachms of chloroform. On examination, the pericardium was healthy, the heart normal in size and position, slight deposit of fat on outside, muscle rather pale, but presenting no distinct evidence of fatty degeneration. Valves all com- petent and healthy; no atheroma of aorta. The lungs were both studded from apex to base with miliary tubercles, and there was an old eavity the size of a walnut in the ape $\mathrm{x}$ of the left. The intestines contained numerous typical tubercular ulcers and many scattered grey tubercles. All the other organs were fairly healthy. In the second case the subject was an emaciated boy aged seven. Here again the heart was healthy; no fatty changes in the muscle; the valves competent and perfectly healthy, with the exception of a very small patch on the anterior flap mitral valve, which appeared slightly thickened. The lungs were extensively diseased, the right being bound down throughout its greater extent with old pleuritic adbesions, and the lung itself collapsed at the base; the left lung was practically absent, being represented by a mass of soft caseous matter. The kidneys were large and congested, the right containing a small abscess. The spleen and liver were large (amyloid). The right knee-joint was one bag of pus with drainage from two places. In both these cases the heart was distinctly noticed to weat after the respiration had ceased, and in both that organ was in a healthy condition, while in both instances there was extensive disease of the lungs, and consequent diminished breathing capacity-in the first case by at least one-third, and in the second by even more than that. The practical inference here is that the lungs have quite as much to do with the risk of chloroform ansesthesia as the heart has; and it is quite as essential that before giving this anæsthetic the lungs should be examined as it is that the heart should be stethoscoped. In both cases death occurred before the intended operation was commenced. St. Helens.

\section{TURNING TWELVE HOURS AFTER RUPTURE OF MEMBRANES.}

BY GEo. H. ButLeR, L. K.Q.C.P.I, L.R.C.S., L.M.

THE following is a report of a case $I$ have recently attended which I think possesses some features of interest.

One morning recently, soon after 5 o'clock, I was called to a case about two miles from my house. The husband, who brought the message, said his wife had been in labour since early in the afternoon of the previous day, that the midwife had been with her all night, and now had sent him for me, as it was a "medical case." He added that a part of the child had been born ever since 5 o'clock of the previous afternoon. I attended as soon as possible, and, on arrival, found the woman to be a multipara, aged forty-two, and on examination found the hand and arm of a fotus protruding from the vulva. The membranes had ruptured about 5 in the afternoon, and almost immediately the hand was protruded from the vagina, and shortly afte:wards the arm as far as the elbow.joint. The woman's strength seemed very well maintained, and the pains had not been very frequent or strong through the night, so $I$ determined to make an attempt to push up the presenting arm and turn. This I was unable to do without chloroform, the uterus becoming strongly contracted round the child as soon as my hand entered it. However, on putting the woman thoroughly under chloroform, after some difficulty and perseverance, I was able to reach a foot and bring it down. Delivery was accomplished in about twenty minutes, there being some delay as the head passed through the brim and outlet. The child was a very large one, and when I saw its proportions I was surprised at the comparative ease with which turning was accomplished after the membranes had been ruptured so long. It was stillborn, and its position in the uterus was abdomino-anterior. The mother is making an excellent recovery. I took care to impress upon the midwife not to delay in sending another time if such a case should come under her notice.

Whitchurch.

The Late Sir Edwin Chadwick.-By the will of the late Sir Edwin Chadwick, of Park Cottage, East Sheen, the Trust Fund (subject to certain specified conditions) is to be applied, as his trustees shall direct, for the advancement of sanitary science; and by a codicil the testator suggests that his trustees may offer a Cup of the value of $£ 20$, to be given annually for a term of years to sanitary authorities at home or abroad showing the greatest reduction in the death-rate of the population in their district. 